\title{
22
}

\section{The European computer driving licence}

\author{
Dudley Dolan \\ ECDL Foundation \\ 2, Blackglen Court, Sandyford \\ Dublin 18, Ireland \\ Tele + 3531294 1997; Fax + 35312941996 \\ E-mail eddf@cs.tcd.ie
}

\begin{abstract}
The European Computer Driving Licence (ECDL) is an international standard of competence for computer users. The ECDL establishes standards for everyone who uses a computer in either a professional or a personal capacity. It is a certificate that verifies competence, declares computer skills and makes the holder readily mobile within business across the European Community. The challenge is to introduce a credible skill certification scheme covering a wide geographical area while still retaining its relevance and quality to local populations.
\end{abstract}

\section{Keywords}

Accreditation, assessment/testing, competencies, skills, standards

\section{INTRODUCTION}

The ECDL is promoted by the ECDL Foundation and has a number of objectives:

1. To raise the level of IT competence within the workforce in industry, commerce and public services throughout Europe;

2. To provide a basis for certifying computer skills in all levels of the education sector and provide a basis for certification of skills for lifelong learning;

3. To reskill the unemployed so that they may re-enter the workforce;

4. To provide an incentive for the disadvantaged to bridge the gap between the haves and the have-nots in the Information Society;

5. to provide an incentive for those outside the workforce, not unemployed, to develop computer skills. 
The ECDL is a basic skill test of the competencies required to perform basic tasks using a personal computer. It provides a documentation that the holder can use a computer in practice and has some background knowledge about IT. The ECDL consists of seven modules covering all major uses of IT in practice and reflects the needs for individuals, small and large companies, and the teaching profession.

Individuals prove their proficiency by passing a test in each module. Progress is registered on a European Computer Skills Card. An ECDL is awarded once all seven module tests have been passed successfully. Except for one theoretical module, the tests are task oriented. The tests are independent of both machine and software vendors and products. The many possible tests within each module, along with a syllabus, constitute an integral part of the ECDL and define a norm for practical IT competence.

The initial geographical extent of the ECDL market is defined as 31 European countries with a total population of about 500 million. Based on generic statistical information, a target group of roughly 60 million may be assumed under current demographic conditions. This is an estimate of the number of individual who employ IT at a level where it constitutes a necessary element in their working activities. The long-term goal for the ECDL efforts is to reach about 10 million of the 60 million by Year 2005, corresponding to a 17\% penetration of today's target group. It is assumed that the public education system will supply the workforce with another 15-20 million skilled entrants. For the business plan period ending in 2001, the goal for the initial phase is about 1.8 million European Computer Skill Cards or Driving Licences issued.

In the short term, the main distribution channel of the ECDL is the body of existing course vendors within each country. Course vendors will see the ECDL as a positive enhancement of their services, being able to market their courses as conforming with and leading to the ECDL. Course vendors will have to be authorized to ensure proper quality of the end product. Authorized course vendors will utilize the ECDL test base in their actual testing. In the longer term Internet will become a major distribution channel, necessitating automation of ECDL testing.

\section{THE ECDL AND THE INFORMATION SOCIETY}
'The emergence of an Information Society in Europe will affect everyone ... the European Union is well placed in comparison with the USA and Japan in public availability of the new generations of digital communications infrastructures. However, Europe is falling behind in business investment in IT and communications equipment for employees, notably office workers, and there are worrying disparities in purchase and use of information technologies and services for personal and home-use between Northern Europe and Southern Europe'.

Arising from the above statement it is recommended that:

- ' 'greater efforts must be made in our schools, to prepare the next generation to participate and benefit fully; 
- greater efforts must be made to stimulate European citizens to create content for new services whether education, entertainment or business;

- continued efforts must be made to keep Europe at the forefront of technology and infrastructure development and deployment for everyone;

- $\quad$ sustained efforts must be made to increase the public awareness of the benefits of active participation in the information society;

- new collective efforts are needed to realize broader social benefits, particularly at local and community level.'

(Bangemann, 1996)

The above extract from the forward by Commissioner Bangemann to the report on The Information Society and The Citizen (1996) raises many points and the European Computer Driving Licence addresses most of the issues and will contribute significantly to the successful development of an all inclusive Information Society.

Over 40 million European households owned a PC in 1994, up from 23 million in 1990. However, the proportion of European households with a PC, and particularly with a networked multimedia PC, is significantly lower than the USA.

Information technologies have already substantially changed the work place in Europe. Over $72 \%$ of office workers have a PC or equivalent on their desks and use it as an integral part of their work.

\section{Varying use of the computers across Europe}

In addition to the above statistics it can be seen that the speed of adoption of the new technologies highlights cultural and linguistic differences between Northern and Southern Europe; more Swedish families bought PCs than TVs in 1995, while fewer than 7\% of households in Spain had a PC in 1994. This situation may well show differences between Western Europe and the CEE Countries when the European Union expands after the new century.

\section{Changes in the workplace}

Each year, on average, more than $10 \%$ of all jobs disappear and are replaced by different jobs in new processes, in new enterprises, generally requiring new, higher or broader skills. There is a much slower pace on the supply side in the acquisition of new skills. Ten years from now $80 \%$ of the technology we operate today will be obsolete and replaced with new, more advanced technologies. By that time, $80 \%$ of the workforce will be working on the basis of formal education and training more than 10 years old. The workforce is aging and the technology is getting younger.

\section{Unemployment}

The area of unemployment is of vital importance and leads to a need for re-training rather than de-skilling. Instead of having 9 million people in long term unemployment and de-skilling, the most expensive form of public spending with the lowest return to the economy or the individual, and many more millions on their way to long term unemployment, the member states of the European Union 
should have 9 million involved in upgrading, maintaining and improving their skills in literacy, numeracy and IT.

The Green Paper, Living and working in the Information Society: People first (1996), says 'It should be a right, an obligation, for all unemployed to maintain and develop basic skills for the Information Society and have them imbued with relevance to the real, dynamic labour market.'

All of the above helps to make the case for lifelong learning. The concept of the ECDL with the European Computer Skills Card to record the acquisition of skills will play a significant role in encouraging people to keep up to date and acquire new skills throughout their lifetime.

The Computer Driving Licence concept was developed in Finland and was introduced in January 1994. It consists of seven modules and is the model on which the ECDL is based. It was introduced with the support of the Ministry of Education, the Central Organization of Finnish Trade Unions, the Confederation of Finnish Industry and Employers, the Finnish Information Processing Association and the Ministry of Labour.

The first Computer Driving Licences, where the candidates passed all seven modules, were awarded in 1994 and 25000 have been issued as of June 1997.

CEPIS (The Council of European Professional Informatics Societies) set up a task force consisting of representatives from ten countries - Norway, Sweden, Denmark, Finland, Netherlands, Ireland, France, Austria, Italy and UK - to consider the increase in competence required for the European workforce. The User Skills task force looked for a suitable model and examined the Finnish CDL in detail. After thorough study it was concluded that the basic Finnish concept was widely applicable throughout Europe, however changes and updates were required.

In order to assess the amount of changes required and the modifications needed to have the ECDL meet the requirements of a wider marketplace a series of pilot tests were carried out in Norway, Sweden, Denmark, France and Ireland. As a result of these tests and a thorough evaluation of the concept, modifications were agreed. A new European Computer Driving Licence Syllabus and European Question and Test Base were developed to meet the newly defined requirements.

The pilot tests gave an opportunity to evaluate the concept from a number of viewpoints. The pedagogical aspects were considered from the point of view of the breadth of knowledge required and the depth of detail needed. The need for the theoretical module was the subject of considerable debate. In the end it was retained.

A method for administering the tests automatically was researched in Sweden and is under extensive evaluation at the moment. It satisfies many requirements and an enhanced version will be introduced in the near future.

In addition to evaluating the tests themselves a period of time was used to establish what the market response would be to such a concept. The response was uniformly optimistic although the numerical forecasts vary considerably due to the different levels of penetration of PCs in the different countries. 
It was clear from our research that industry felt a need for some sort of certification to ensure that their investment in training was worthwhile. Individuals welcomed the opportunity to show that they had acquired some skills, which they perceived to be vital in the current information society.

Course vendors were happy with the concept as it gave them a focus for their course offerings. Government, employers and trade union organizations in many countries found the concept attractive. In particular, the Irish Congress of Trade Unions (ICTU) was very supportive. Ministries of Education in a number of countries gave active support. In Denmark a government-supported regional initiative was undertaken.

The ECDL project has been funded by various sections of the European Commission. These include the DGIII ESPRIT programme, DGV European Social Fund and DGXXII LEONARDO programme.

The ECDL Foundation is involved as a partner in a number of other proposals submitted to the ESPRIT programme. In addition to support from the European Commission and National Government departments the project has created great interest in many large multinational organizations, including $\mathrm{ABB}$, Ericsson, IBM, Microsoft, Rank Xerox and Norsk Hydro.

The establishment of the ECDL Foundation in Ireland in January with a small staff created the platform for the development of the ECDL and the implementation of the ECDL concept throughout Europe. The ECDL Foundation will monitor the quality and ensure the adherence to standards throughout Europe.

There are four basic components which comprise the ECDL:

1. The European Computer Driving Licence (ECDL)

This is the document which indicates that the holder has satisfactorily completed all seven modules of the European Computer Driving Licence. The document will have a similar format throughout Europe. It will bear the name 'European Computer Driving Licence' in English and also the name by which it is known in each individual country.

\section{The European Computer Skills Card (ECSC)}

The ECSC is a document which is used to record the progress of the candidate and the dates on which each of the seven modules were completed. When all seven modules are completed the candidate will return the completed European Computer Skills Card to the National European Computer Driving Licence Centre and a European Computer Driving Licence will be issued.

The modules can be taken in any sequence and the tests can be taken in different test centres and indeed in different countries.

\section{The ECDL Syllabus}

The ECDL Syllabus describes the objectives, content and guidelines for assessment of each of the seven modules of the ECDL. The ECDL 
Syllabus version 1 was published in October 1996 and represents one of the outcomes of the work of the ECDL Task Force during 1996.

The Syllabus will be updated on a continual basis and new versions will be issued at least once per year. The Syllabus represents the norm for IT skills requirements throughout Europe and as such it will be used as the basis for both conventional and Computer-Based Training, which will lead to the attainment of the ECDL.

\section{The European Question and Test Base (EQTB)}

The EQTB is the set of questions and tests which candidates must pass in order to attain an ECDL. There are some 100 questions for module 1 and approximately 20 tasks for each of the practical tests. The EQTB sets a test norm which may be implemented by a number of systems including manual, semi-automatic and fully automatic.

The time allowed for each of the test modules is 45 minutes.

In addition to the four components listed above there will also be a number of associated products and services including the authorization of organizations wishing to conduct tests for the ECDL. Also assistance and consultancy services will be offered to intending licensees.

Income will be generated mainly from licence fees from the sale of European Computer Skills Cards.

The tests are carried out using a PC. Tests can be for individuals, or more typically, for groups consisting of from 5-20 persons. The results are recorded in electronic form and the candidates actually carry out real tasks. The tests and exercises ask the candidates to do something rather than asking do they know how to do it.

The tests for ECDL will be conducted by authorized test centres. These centres will be validated by the licensee in each country using guidelines provided by the ECDL Foundation. The test centres are expected to be operated by course vendors, educational establishments, and large organizations or companies.

It is the intention that authorized test centres should provide facilities to test not only their own pupils but also persons who wish to take a test without undergoing formal courses.

Quality will have a high priority and quality assurance procedures will be instituted in the ECDL Foundation, the licensees and sub-licensees and the test centres. The quality assurance procedures will include use of rigorous implementation of standard authorization guidelines.

The results of the tests across Europe will be monitored on a statistical basis and any unusual patterns will be investigated by the ECDL Foundation. Strict adherence to the syllabus and the use of approved EQTB's will also ensure that the tests will be of an even standard. The ECDL Foundation will perform an audit function to ensure that standards are maintained and that the quality of the product is ensured. 


\section{Development and updating}

The ECDL Foundation will ensure that the ECDL Syllabus and EQTB are updated on a regular basis to ensure that they always reflect the needs of the marketplace and the persons who are taking the tests. This updating will ensure that the product reflects the latest developments in the software available by modifying the existing modules, and will also cater for new developments by introducing new modules if and when required. Integration of existing modules could also take place if market forces so demand.

There will be a Members Forum which will give a platform for licensees, sublicensees and test centres to share experiences and to suggest any developments which they feel are appropriate. This will ensure that the products are updated and developed in line with market requirements.

\section{Automation}

A priority in 1997 will be to ensure that the testing process is automated to the fullest possible extent. This is seen to be vital in the light of the volumes of persons to be tested, which should be some hundreds of thousands initially and ultimately will be millions. The feasibility of taking tests over the Internet from work or home will also be investigated as will diagnostic tests which will point to the areas of weakness of each candidate rather than the current pass/fail testing process.

There is a window of opportunity for this product at the moment. It is essential that it quickly gains acceptance as the test of skills in Europe. There are already optimistic signs that this will be achieved. The support of the European Commission through funding from the ESF, DGIII, DGXXII gives the ECDL considerable credibility. In addition, the fact that it is included in the Information Society Action Plan prepared by Commissioner Bangemann for Central and Eastern European Countries adds to this.

Acceptance by the large employers and support from the Ministries of Education, Labour and Industry in many countries has greatly added to the credibility of the European Computer Driving Licence and its associated products.

\section{REFERENCES}

Bangemann, M. (1996) Foreword, in The Information Society and The Citizan: A status report on the availability and use of information and communcation systems. A report by the Commission Services, Brussels, Belgium.

Commission of the European Community. (1996) Living and working in the Information Society: People first. A Green Paper of the Commissin of the European Communities, Brussels, Belgium. 


\section{BIOGRAPHY}

Dudley Dolan was educated at Trinity College Dublin and graduated in 1962 with an honours degree in Production Engineering. He joined IBM on graduation and spent twenty years working in the computer industry in various positions. He joined the staff of Trinity College in 1983 and has been responsible for a B.Sc. Degree in Computer Science since then. In February 1997 he commenced two years leave of absence from Trinity College to act as a Managing Director of the ECDL Foundation.

He is a past President of the Irish Computer Society and he was a trustee of IFIP from 1989 to 1996. He was a Vice President of the Council of European Professional Informatics Societies (CEPIS) from 1992 to 1995. 